\title{
Early Development of Verb-constructions in an English-speaking child
}

\author{
Insa Gülzow \\ ZAS BERLIN \\ guelzow@zas.gwz-berlin.de
}

\section{Introduction}

In this paper the first results concerning the development of early verb morphology in an L1English speaking child are presented. Adopting the framework of morphological development of Dressler (Dressler, this volume) the data of a girl from the CHILDES database, Nina of the Suppes corpus, is analysed with regard to the emergence of early verbal categories (e.g. number and person) and their appearance in a first mini-paradigm. In the sessions analysed so far the child Nina has reached an age of 2;2 when the first mini-paradigm emerges.

\section{Description of verb morphology in the target language}

English is a language which has lost most elements of its once rich inflectional system. All in all about ten inflectional suffixes have survived the Middle English period when most inflections were lost. Verb morphology is reduced to a few suffixes marking person, number, tense and aspect. In the absence of inflectional suffixes, the categories person and number are mainly marked by personal pronouns; English auxiliaries also mark person and number along with tense, mood and voice. The morphology of English auxiliaries is opaque and a number of syncretic forms exist. Present indicative presents the only case in which person and number are marked simultaneously by a suffix: third person singular invariably occurs with the inflection $-s$ (table 1). Past tense forms are in the case of regular verbs identical with the past participle (table 2) and are marked for tense only. Some past tense forms/past participles display an opaque or suppletive morphology. Progressive aspect is constructed analytically and consists of the present participle marked by the ending -ing and a finite form of the verb to be. In the case of present progressive this is the present participle and a present finite form of the verb to be (table 3 ). In the present study only a few constructions are relevant. The child in this study used the infinitive form of verbs and the present participle which later on occurred in target like present progressive constructions. Some regular and some overgeneralized past tense forms occurred. Third person singular $-s$ was used sporadically but not in a systematic way until the end of the recordings analysed in this study. Some modal and some future constructions were used which will be discussed separately. The finite forms of the verbs to have and to be are relevant for analytical tenses and are displayed in table 4.

Table 1: present indicative: to walk

\begin{tabular}{|l|ll|l|}
\hline & \multicolumn{2}{|l|}{ singular } & plural \\
\hline 1st & I walk & we walk \\
\hline 2nd & you walk & you walk \\
\hline 3rd & s/he, it walk-s & they walk \\
\hline
\end{tabular}

Table 2: simple past: to walk

\begin{tabular}{|l|ll|ll|}
\hline & \multicolumn{2}{|l|}{ singular } & plural & \\
\hline Ist & I & walk-ed & we & walk-ed \\
\hline 2nd & you & walk-ed & you & walk-ed \\
\hline 3rd & s/he, it walk-ed & they & walk-ed \\
\hline
\end{tabular}


Apart from pronominal elements English noun phrases are not inflected for case. The personal pronouns of first and third person singular and plural differ in nominative and objective case. Consequently, word order is crucial for identifying the subject in a sentence. English sentences must have subjects which occur at the beginning of a sentence. Unless a sentence is passive, the most agentive member will appear in subject position. As will be explained in more detail in section 4 , only imperatives and those utterances of the child which contained a verb plus a subject were considered for analysis.

Table 3: present progressive: to walk

\begin{tabular}{|l|l|l|}
\hline & singular & plural \\
\hline 1st & am walk-ing & are walk-ing \\
\hline 2nd & are walk-ing & are walk-ing \\
\hline 3rd & is walk-ing & are walk-ing \\
\hline
\end{tabular}

Table 4: the verbs to be and

\begin{tabular}{|l|l|l|}
\hline & singular & plural \\
\hline 1st & am & are \\
\hline 2nd & are & are \\
\hline 3rd & is & are \\
\hline
\end{tabular}

to have
\begin{tabular}{|l|l|}
\hline singular & plural \\
\hline have & have \\
\hline have & have \\
\hline has & have \\
\hline
\end{tabular}

\section{Data description}

The data were taken from the CHILDES database. For the present study the first fifteen recordings of the girl Nina of the Suppes corpus were analysed. In the first session of the recordings, Nina still produces a lot of one-word-utterances, but has begun to put words together in longer sequences and also uses a number of verbs. The first recording takes place at Nina's home with only her mother being present. Other sessions were taped when Nina's grandparents or some of her friends were visiting.

Table 5: age at recording and number of child utterances

\begin{tabular}{|c|l|c|}
\hline $\begin{array}{l}\text { number of } \\
\text { recording }\end{array}$ & age & $\begin{array}{l}\text { total number of } \\
\text { utterances }\end{array}$ \\
\hline 1 & $1 ; 11,16$ & 815 \\
\hline 2 & $1 ; 11,24$ & 572 \\
\hline 3 & $1 ; 11,29$ & 790 \\
\hline 4 & $2 ; 0,3$ & 739 \\
\hline 5 & $2 ; 0,10$ & 394 \\
\hline 6 & $2 ; 0,17$ & 272 \\
\hline 7 & $2 ; 0,24$ & 797 \\
\hline 9 & $2 ; 1,6$ & 584 \\
\hline 10 & $2 ; 1,15$ & 781 \\
\hline 11 & $2 ; 1,22$ & 700 \\
\hline 12 & $2 ; 1,29$ & 687 \\
\hline 13 & $2 ; 2,6$ & 758 \\
\hline 14 & $2 ; 2,12$ & 739 \\
\hline 15 & $2 ; 2,28$ & 716 \\
\hline 16 & $2 ; 3,5$ & 620 \\
\hline & & \\
\hline
\end{tabular}




\section{Predecessors of verbs in predicative function}

At the onset of the recordings $(1 ; 11,16)$, Nina is already using a number of lexical verbs. In early stages of language development, relational words such as more, gone or prepositions such as in and out can also be considered verbs as long as their conceptualization is a process and their use is as a predicate (Tomasello 1992). Often documented as predecessors of verbs these expressions still exist in the data of Nina. Only some can be discussed briefly.

Initially, more was used to indicate general recurrence of objects (1), food (2) and activities (3). In session 9 Nina begins to use more as a quantificational modifier as demonstrated by her use of it in utterances containing a 'true' verb (4). From session 10 onwards the majority of utterances containing more also has a verb (5)-(6).

(1) ${ }^{*}$ CHI: more rabbit.

(2) ${ }^{*} \mathrm{CHI}$ : more cookie.

(3) ${ }^{*} \mathrm{CHI}$ : more reading.

${ }^{*} \mathrm{CHI}$ : my want more coffee

(5) ${ }^{*} \mathrm{CHI}$ : my have more things in my box. *CHI: he got more food.

If context is lacking, it is not always easy to decide if a preposition is used as a verb or not. Most utterances in which a preposition seems to be used as a verb (7a) and (8a) are constructed parallel to other utterances which are produced by Nina with a lexical verb in place of the preposition (7b), (7c), (8b), (8c). Utterance (9) was produced by Nina when she was getting up, because she wanted to go out. That prepositions are indeed conceived as verbs by children is illustrated in (10) where Nina productively uses the suffix of the present participle. The utterance was a comment of Nina at age $2 ; 0,3$ as she watches her mother taking the pieces of a puzzle out. The production of the non-target form outing will be discussed in section 4.2.2 since it serves as an example that Nina is capable of some morphological generalization in a phase of language acquisition when she is not yet making use of a more complex system of English verbal affixes. It is hard to say at which point Nina stops to use prepositions in place of verbs, but in the course of the recordings, examples such as (7a), (8a) and (9) become less frequent and even if an utterance is produced without a verb, the preposition tends to occur as an appropriate member of a prepositional phrase (11).
(7a) ${ }^{*} \mathrm{CHI}:$ off Mommy
$(2 ; 0,17)$
(7b) ${ }^{*}$ CHI: draw \# Mommy
$(2 ; 0,24)$
(7c) ${ }^{*} \mathrm{CHI}$ : talk Mommy
$(2 ; 1,6)$
(8a) ${ }^{*} \mathrm{CHI}$ : off a eye (poking teddy's eyes)
(8b) ${ }^{*} \mathrm{CHI}$ : pulling a bus
(8c) ${ }^{*}$ CHI: see the nail
(9) * CHI: out up.
(10) ${ }^{*} \mathrm{CHI}$ : Mommy's outing.
$(2 ; 0,3)$
(11) ${ }^{*} \mathrm{CHI}$ : on the chimney

\section{Emergence of verb-forms}

\subsection{General remarks}

English is a language with little morphology and thus only a few verbal inflections. Of the languages which are analysed in this volume, English represents one end of the continuum and can be characterized as an isolating rather than a synthetic type of language regarding its 
verbal morphology. Throughout the discussion of the results of the present analysis, it should be born in mind that the first mini-paradigms in two children acquiring French (Kilani-Schoch, this volume), a language with almost equally poor verb inflection, were identified when the children reached an age of $2 ; 0,22$ and $1 ; 8,10$. Regarding the first emergent categories, the data of Nina will be compared to that of a child acquiring a language with a relatively rich morphology: the German child Anna (Bittner, this volume).

The main area of verbal morphology in English are the inflectional endings -ing, - ed and $-s$ and the auxiliaries of the compound tenses. From the onset of the study, Nina uses two main verb forms: the root infinitive (12)-(13) and the present participle (14)-(15), a quantitative analysis can be found in table (10)-(11). The first fully inflected forms that appear with some regularity are analytical constructions with third person singular present progressive verb forms (16)-(18).

(12) * CHI: bunny dance too.

(13) *CHI: drink dolly.

(14) *CHI: bunny dancing.

(15) * CHI: drinking dolly

*CHI: he's sleeping.

(17) * ${ }^{*} \mathrm{HI}$ : he's eating his cereal.

${ }^{*} \mathrm{CHI}$ : he is sleeping.

As will be discussed in more detail below, the use of the present participle is at first limited to a certain verb group. Although the present participle appears almost always in target like constructions, non-target root infinitives appear just as likely'. It thus seems to be the case that the child's use of the present participle is still an example of rote learning and that to a certain degree the two forms are no more than optional variants at this stage. A closer look at the data will reveal that despite the similarities in the use of the two verb-forms in early stages of acquisition, even in the first sessions of the recordings the -ing form shows some definite signs of specification in terms of the categories person and number. For a target like use of the root infinitive a number of options are given in English. In the simple present (table 1) it is the target form for all persons and numbers but third person singular. The root infinitive is also used as both singular and plural imperative, in the future tenses and in modal constructions. Despite these numerous possibilities, use of the root infinitive is almost only target like in Nina's utterances when used as an imperative. In the first sessions of the recording she uses neither future tense nor modal constructions. Her use of the root infinitive as a form of the present indicative can also be ruled out in the majority of cases. Apart from a few verbs that cannot be used in the progressive, a closer look at the constructions involving the root infinitive will reveal that they are almost never instances of the simple present (cf. 4.2.2). It will thus be argued that in contrast to the -ing form which is mainly used with third person singular referents the root infinitive is used as a default form in all other cases.

\footnotetext{
${ }^{1}$ The following example from the first session of recording shows that the infinitive form and the -ing form are used in an identical context. $\quad{ }^{*} \mathrm{CHI}$ : drink \# Nina.

*MOT: Nina's going to drink?

*MOT: oh \# is it good?

*CHI: drink dolly.

*MOT: what are you drinking now?

*CHI: drinking dolly.
} 
For the following presentation of the results it is important to understand the criteria that were used to identify possible candidates for the first mini-paradigm. At the onset of the study the child Nina uses the -ing form of verbs without an accompagnying finite verb form (14)-(15). She only later produces utterances in which the present participle appears together with either a full (18) or an affixed version of an auxiliary (16)-(17). Although the very first appearances of the present participle are clear instances of rote learning (s.a.) the use of inflectional -ing versus the root infinitive is the first morphological contrast that is soon established in Nina's system. It will be argued that Nina's entry into English verb morphology is marked by the use of the inflectional suffix -ing. In the present analysis the use of the present participle will be recognized as a prestep before the appearance of first mini-paradigms. Within the phase of protomorphology the present participle begins to appear with an auxiliary which opens up the possibility of morphosemantic contrasts concerning the categories person and number and eventually tense. It will be shown that the verb-forms used in (16)-(18) are the first candidates that qualify for a position in a mini-paradigm.

Although Nina's first use of the aspectual marker -ing contrasts with the use of the root infinitive it does not contrast within a category as long as the auxiliary is missing. This is an important point to note since a couple of recordings pass before Nina begins to use other suffixes in any relevant numbers. It is thus possible that an English child acquires -ing without being aware that the suffix is part of a verbal morphological system. This is true even in the case of English where verbal morphology is reduced to only a few distinctions. Since the appearance of mini-paradigms should be an indicator of morphosemantic oppositions within the stage of protomorphology it makes little sense to argue that the child is beginning to discover paradigmatic relationships if the non-contrastive affix -ing is acquired in isolation. This is to say that while the verb-form used in (14)-(15) will not qualify as candidates for a mini-paradigm, the verb-form used in (16)-(17) (and (18) of course) will, since it is in theoretical contrast with other morphologically marked forms (e.g. ' $m$ sleeping/am sleeping or 're sleeping/are sleeping). As a closer look at the data will show, Nina starts off by using the -ing form of verbs for reference to third persons singular. A contrast to other persons and number slowly emerges as the use of -ing with third person singular becomes more target like through the use of agreement markers (auxiliaries) which licences morphosemantic oppositions and thus first contrasts in a mini-paradigm.

The second aspect that needs to be mentioned is that due to the lack of inflectional distinctions there are numerous syncretic verb forms in English (tables 1-3). The root infinitive for instance is used both as singular and plural imperative, appears in modal and future constructions and is used for all persons and numbers despite third person singular in the present indicative (table 1). In the present analysis verb forms were regarded as possible candidates for a mini-paradigm if they encoded different categories such as imperative versus present indicative. Syncretic forms within categories (such as first and second person singular present indicative) were not given independent status in a mini-paradigm if they collapsed two or more potential contrasts in one verb-form. In table 3 the six slots of the paradigm are filled. In the present analysis it is assumed that the child needs to learn that first person singular combines with the auxiliary am while third person singular combines with the auxiliary is. The verb forms am walking and is walking represent two possible slots in a mini-paradigm. These two instances contrast with all other cases in which the auxiliary are has to be used. The production of are would thus be counted as usage of one inflected form only. In this sense, the first paradigm which meets both the criteria of the present analysis and the framework adopted here (Dressler \& Kilani-Schoch 2000) appears when the child Nina reaches an age of $2 ; 2$. 
A last remark must be made concerning coding procedures. Only those utterances of Nina were coded that could be identified as imperatives or which had subjects. Even if some contextual information is given, in most cases it is impossible to decide whether utterances such as (19)-(21) are comments on what the child is doing herself or a comment on what the mother or other person is doing if no subject is mentioned. Unless the child is using non-target person references (cf. pronoun-reversing children), subjects are a reliable indicator of the categories person and number.

${ }^{*} \mathrm{CHI}$ : fit here.

(20) *CHI: feed the llama.

(21) *CHI: throw on Nina's hand.

$(2 ; 0,10)$

\subsection{Premorphology}

\subsubsection{Formal characteristics}

In the first eleven sessions of the recordings before the child Nina reaches an age of 2;2 she uses a variety of different verbs. These are mostly lexical verbs, but also some relational words and prepositions used in a predicative function. Of the inflectional endings which occurred, -ing is the dominant one (tables 10-13). Occasionally the child Nina uses third person singular $-s$, in the majority of cases with appropiate third person singular subjects although not always in target like constructions. The relatively high token number of third person singular $-s$ (table 12) in the first session are all instances of use with the same verb and were produced in only one context. Since no other verbs with third person singular $-s$ occurred in this or the subsequent sessions in any high numbers it is doubtful that the suffix is used productively.

Occasional past tense forms/past participles occurred, these were mostly examples of non-regular past formation (22)-(25). Of the verbs which were used with the suffix -ing all belonged to the semantic category of activity verbs in the first recorded sessions, like to swim, to dance, to eat, to drink, to sleep. None of these occurred only with the ending -ing, but also in the infinitive. Vice versa, some verbs which occurred in the infinitive were never used in the progressive form. These were predominantly change-of-state verbs like to close, to open, to break, achievements like to find, to get. Prepositional verbs like to fall down and to lie down where used in the progressive form in later sessions from age $2 ; 1,15$ onwards (26)-(27).

(22) ${ }^{*} \mathrm{CHI}$ : Nina ate my food.

(23) * CHI: duck ate my food.

(24) *CHI: box called a cage? $\quad(1 ; 11,29)$

(25) *CHI: Ellie gave my balloon.

(26) *CHI: I sliding down.

(27) *CHI: I taking something out.

$(2 ; 1,29)$

\subsubsection{Form-function analysis}

For reasons mentioned above, only imperatives and those utterances which contained a verb plus an identifiable subject were considered in the analysis. The results of the

English-speaking child Nina are summed up in tables (10)-(13). Regarding the emergence of categories, three interesting observations can be made. First, tables (10)-(13) show that the vast majority of person references are first and third person singular references. Occasional usages of second person singular and third person plural are documented. Second, the child uses imperatives. Imperatives are always produced with the infinitive form of the verb, never 
the -ing form. Third, occasional past tense references can be observed. Most of these are irregular past tense forms, often used context bound.

It has already been mentioned that the data represented in table 10 contains predominantly non-target utterances. While this is straightforward in the case of third person singular where inflectional $-s$ is missing, this might not be as obvious in the case of first person singular references. The examples given in (28)-(30) show that the use of the simple present might look target like on a formal basis but seldom is in the discourse of the child. All utterances are comments on the child's activities. In many instances more than one interpretation is possible concerning the fact whether the child has just completed an action, is commenting on an ongoing action or anticipating an action. Despite these various possibilities use of the root infinitive form of the verb is not target like in any one of them.

$$
\begin{aligned}
& { }^{*} \mathrm{CHI}: \text { my make a house. } \\
& { }^{*} \mathrm{CHI} \text { : me eat (th)em. } \\
& { }^{*} \mathrm{CHI}: \text { I slide down too. }
\end{aligned}
$$

A closer look at form-function relationships within the two main verb forms used by Nina shows that there are two interesting parallels to the German child Anna's data (Bittner, this volume). The general trend of form-function pairings in table (10) and (11) can be summed up as follows: the child Nina uses two general verb-forms for present tense references, the infinitive and the -ing form. While both are not specified in terms of person and number, one of the two verb-forms is more general than the other, this is the infinite form of the verb. The use of the infinitive form is spread more general across person and number categories while the -ing form is mainly used for third person singular references. The main contrast that Nina establishes at this stage of development is a proximal - non-proximal one. While the root infinitive appears as a default form in all cases that have not yet been specified, the -ing form is almost entirely reserved for third person singular reference. In other words, reference to a non-proximal participant that is a member of the child's discourse and thus is neither speaker

\begin{tabular}{|c|c|c|c|c|c|c|}
\hline age & \multicolumn{5}{|c|}{ present } & $\mathrm{imp}$ \\
\hline & $1 \mathrm{sg}$ & $2 \mathrm{sg}$ & $3 \mathrm{sg}$ & $1 \mathrm{pl}$ & $3 \mathrm{pl}$ & \\
\hline $1 ; 11,16$ & & & $6 / 12$ & & $1 / 1$ & $5 / 11$ \\
\hline $1 ; 11,24$ & $3 / 3$ & & $3 / 9$ & & $1 / 1$ & $5 / 10$ \\
\hline $1 ; 11,29$ & $4 / 6$ & & $16 / 30$ & & $2 / 2$ & $3 / 11$ \\
\hline $2 ; 0,3$ & $2 / 3$ & & $5 / 13$ & & & $6 / 7$ \\
\hline $2 ; 0,10$ & $9 / 26$ & & $6 / 7$ & & $1 / 1$ & $2 / 3$ \\
\hline $2 ; 0,17$ & $2 / 4$ & & $1 / 2$ & & & $6 / 10$ \\
\hline $2 ; 0,24$ & $4 / 5$ & & $10 / 18$ & & & $11 / 42$ \\
\hline $2 ; 1,6$ & $9 / 10$ & & $7 / 10$ & & & $2 / 3$ \\
\hline $2 ; 1,15$ & $20 / 32$ & $4 / 6$ & $10 / 20$ & $1 / 1$ & $1 / 1$ & $9 / 12$ \\
\hline $2 ; 1,22$ & $18 / 45$ & $3 / 6$ & $9 / 14$ & & $1 / 3$ & $6 / 17$ \\
\hline $2 ; 1,29$ & $15 / 27$ & $6 / 7$ & $13 / 34$ & & $1 / 1$ & $9 / 13$ \\
\hline
\end{tabular}
nor hearer is marked by the use of a first verbal affix: the -ing form of the verb.

Table 10: infinitive verb forms with subject (lemmas/tokens)

A similar picture emerges in the first recordings of the German child. In the first recorded sessions, Anna also refers mainly to herself and third persons in the singular. Plurals are rare and second person reference is almost non-existent. Just as Nina, Anna mainly uses two 
inflectional categories for person reference, of which one is the infinitive form of a verb and the other inflectional $-t$, which is the appropiate marker for third person singular present indicative. Anna's use of the infinitive form is more generally spread across the categories person and number and the suffix $-t$ is mainly reserved for third person singular reference. While the emergence of similar categories in both the German and the English child is not surprising, it seems interesting that at early stages of acquisition there are some striking similarities in the form-function pairings of the two children. Concerning their degree of verbal inflection, German is a much richer language than English. Although the verbal system of the two languages is fairly similar in terms of structure (similar categories are marked by similar means), the mechanisms of acquisition will have to diverge at some point.

Nevertheless, the children's entry into the verbal inflectional system of their languages shows some similar characteristics. Two general inflectional categories are established of which one has the form of the infinitive and is used as a default form. Since the main participants the child refers to in her discourse are first and third persons singular, both the English and the German child end up with non target structures when using the infinitive ${ }^{2}$. The other inflectional categories, -ing in English and $-t$ in German, already show a tendency towards specification of third person singular. While in German this usage is the target like use of a synthetic tense, in English the child still has to acquire the agreement part of the analytical construction.

Table 11: -ing verb forms with subject (lemmas/tokens)

\begin{tabular}{|c|c|c|c|c|c|}
\hline age & \multicolumn{4}{|c|}{ present } & $\mathrm{imp}$ \\
\hline & $1 \mathrm{sg}$ & $2 \mathrm{sg}$ & $3 \mathrm{sg}$ & $3 \mathrm{pl}$ & \\
\hline $1 ; 11,16$ & $1 / 3$ & & $3 / 6$ & $1 / 2$ & \\
\hline $1 ; 11,24$ & & & $1 / 3$ & & \\
\hline $1 ; 11,29$ & & & $5 / 29$ & $2 / 2$ & \\
\hline $2 ; 0,3$ & $1 / 1$ & & $13 / 22$ & $2 / 2$ & \\
\hline $2 ; 0,10$ & $1 / 1$ & & $3 / 3$ & & \\
\hline $2 ; 0,17$ & $2 / 2$ & & $1 / 1$ & $1 / 1$ & \\
\hline $2 ; 0,24$ & $1 / 1$ & & $3 / 8$ & & \\
\hline $2 ; 1,6$ & & & $4 / 6$ & & \\
\hline $2 ; 1,15$ & $1 / 1$ & $1 / 1$ & $4 / 6$ & & \\
\hline $2 ; 1,22$ & $1 / 1$ & & $1 / 1$ & $1 / 1$ & \\
\hline $2 ; 1,29$ & $3 / 4$ & & $6 / 13$ & $1 / 1$ & \\
\hline
\end{tabular}

It should be mentioned at this point that although the child Nina has not established more than one morphological contrast in her verbal system at this stage there are clear signs that some generalization process is taking place and that the suffix -ing is given a morphosemantic status. Apart from the example which was stated in (10), Nina produces two more creative usages of the suffix -ing. The example in (31) is produced while Nina is looking at a bug that is walking on an apple, (32) while she is looking at a picture in which a dog is sleeping in a house the door of which is closed, Nina is pointing at the keyhole:

*CHI: bugging.

*CHI: locking.

\footnotetext{
${ }^{2}$ See (28)-(30) why the infinitive form used as first person singular present indicative is considered a non target formation in the English data.
} 
Both examples involve the use of the suffix -ing together with what is categorized as a noun in the target system. Although it is impossible to tell what Nina's exact intended meaning is, in both cases it is quite possible to identify an event in the context that could have been intended by her. Concerning her early specification of -ing, the two instances are consistent with her system, both referents are third person singular.

Table 12: -s verb forms with subject

\begin{tabular}{|l|l|l|l|}
\hline age & $1 \mathrm{sg}$ & $3 \mathrm{sg}$ & $3 \mathrm{pl}$ \\
\hline $1 ; 11,16$ & & $1 / 6^{3}$ & \\
\hline $1 ; 11,24$ & & $1 / 1$ & \\
\hline $1 ; 11,29$ & & & \\
\hline $2 ; 0,3$ & & & \\
\hline $2 ; 0,10$ & & & \\
\hline $2 ; 0,17$ & & & \\
\hline $2 ; 0,24$ & & $1 / 1$ & \\
\hline $2 ; 1,6$ & & & $1 / 1$ \\
\hline $2 ; 1,15$ & & & \\
\hline $2 ; 1,22$ & $1 / 1$ & & \\
\hline $2 ; 1,29$ & & & $1 / 1$ \\
\hline
\end{tabular}

Table 13: Past verb forms with subject

\begin{tabular}{|l|l|l|l|l|}
\hline age & \multicolumn{2}{|c|}{ past } & & \\
\hline & $1 \mathrm{sg}$ & $2 \mathrm{sg}$ & $3 \mathrm{sg}$ & $3 \mathrm{pl}$ \\
\hline $1 ; 11,16$ & & & & \\
\hline $1 ; 11,24$ & & & & \\
\hline $1 ; 11,29$ & $1 / 1$ & & $2 / 3$ & \\
\hline $2 ; 0,3$ & & & $1 / 1$ & \\
\hline $2 ; 0,10$ & & & & \\
\hline $2 ; 0,17$ & & & $1 / 1$ & \\
\hline $2 ; 0,24$ & & & $1 / 13$ & \\
\hline $2 ; 1,6$ & $1 / 1$ & & $1 / 1$ & \\
\hline $2 ; 1,15$ & $2 / 5$ & & $2 / 3$ & \\
\hline $2 ; 1,22$ & $3 / 6$ & & $2 / 2$ & $1 / 2$ \\
\hline $2 ; 1,29$ & & & & \\
\hline
\end{tabular}

It has already been mentioned that the first mini-paradigm which can be identified in the data of Nina is produced when she reaches an age of $2 ; 2$. As was already illustrated in tables (10)-(13), in the eleven sessions befor age 2;2 a number of categories emerge in the data of Nina. Table (14) shows a listing of both the categories which were documented in each of the sessions by Nina's use of verbs (marked by an X) and their manifestation in the first inflected verb forms (marked by two XX). Of all inflected verb forms which were considered, many were imitated or formulaic. All forms were isolated occurrences. In many instances production was context-bound. For instance, in the seventh session at an age of 2;0,24 Nina produced eleven different utterances containing the past tense from gave. All her utterances were organized around a special context, that of being given presents. Some examples are given in (33)-(35).

\footnotetext{
${ }^{3}$ These are all instances of the same verb, s.a.
} 
It is an interesting point to note that of the categories that emerge in the premorphological phase of Nina's development, most are represented as inflected verb forms and can thus be regarded as predecessors of the first mini-paradigms. As table 14 shows, categories that emerge late will also surface later as inflected verb forms. The most striking difference between early emergent categories and inflected verb forms represented in table 14 is the mismatch concerning the category first person singular. While many references are made to herself by Nina (table 10), inflected first person singular verb forms are not used consistently (table 14). As table 11 shows use of the -ing form when making a first person singular reference is reduced to one or two verb types per session. This is in sharp contrst to the use of the -ing form with third person singular referents which appear with numerous verb types in the majority of the recorded sessions.

Table 14: emergent categories in pre-morphology

\begin{tabular}{|c|c|c|c|c|c|c|c|c|c|c|c|}
\hline & & & & \multicolumn{3}{|c|}{$\mathrm{sg}$} & \multicolumn{3}{|c|}{$\mathrm{pl}$} & & modal \\
\hline & PAST & PRES & FUT & $1 \mathrm{st}$ & 2nd & $3 \mathrm{rd}$ & $1 \mathrm{st}$ & 2nd & $3 \mathrm{rd}$ & IMP & \\
\hline $1 ; 11,16$ & $\mathrm{X}^{4}$ & $X X$ & & $\mathrm{XX}$ & & $X \times$ & & & $x \times$ & $X X^{3}$ & \\
\hline $1 ; 11,24$ & $\mathrm{X}$ & $\mathrm{XX}$ & & $\mathrm{X}$ & & $x \times$ & & & $X$ & $\mathrm{XX}$ & \\
\hline $1 ; 11,29$ & $x \times$ & $\mathrm{XX}$ & & $\mathrm{X}$ & & XX & & & XX & $x \times$ & $\mathrm{XX}$ \\
\hline $2 ; 0,3$ & $\mathrm{XX}$ & $\mathrm{XX}$ & & XX & & XX & & & XX & $x \times$ & \\
\hline $2 ; 0,10$ & $\mathrm{X}$ & XX & & $\mathrm{XX}$ & & XX & & & $\mathrm{X}$ & XX & \\
\hline $2 ; 0,17$ & $\mathrm{XX}$ & $\mathrm{XX}$ & & $\mathrm{XX}$ & & $\mathrm{XX}$ & & & $\mathrm{XX}$ & XX & \\
\hline $2 ; 0,24$ & $\mathrm{xx}$ & $x \times$ & & $\mathrm{XX}$ & & $\mathrm{XX}$ & & & & $\mathrm{XX}$ & \\
\hline $2 ; 1,65$ & $\mathrm{x}$ & XX & & $\mathrm{X}$ & & XX & & & & XX & \\
\hline $2 ; 1,15$ & $x \times$ & XX & & $X X$ & $\mathrm{XX}$ & XX & & $\mathrm{X}$ & $\mathrm{X}$ & $\mathrm{XX}$ & \\
\hline $2 ; 1,22$ & $\mathrm{XX}$ & $x x$ & $\mathrm{X}$ & $\mathrm{XX}$ & $\mathrm{X}$ & XX & & & $X X$ & $\mathrm{XX}$ & $X X$ \\
\hline $2 ; 1,29$ & $X$ & $x \times$ & $\mathrm{X}$ & XX & $\mathrm{X}$ & XX & & & $\mathrm{XX}$ & $X X$ & \\
\hline
\end{tabular}

Summing up the results so far, it can be said that in Nina's premorphological phase a number of categories are established. Concerning the category of person, the dominant referents are third persons singular, followed by reference to self. If imperatives are regarded as a separate category, reference to second person singular is established last. The same trend can already be observed for plural references. Reference to third person plural is the first to be used. In the light of what has just been said, it is an interesting question to ask what the third person singular references involving an -ing form exactly look like. For this purpose the recorded

\footnotetext{
${ }^{4}$ Many of the default verb forms in the root infinitive have a perfective meaning in the sense that an action had just been completed. $\quad$ *MOT: what happened to the blocks?

${ }^{*} \mathrm{CHI}$ : gone.

*MOT: they're gone?

*MOT: what happened to them?

${ }^{*} \mathrm{CHI}$ : fall down.

(Nina $1 ; 11,24)$
}

\footnotetext{
${ }^{5}$ Verb forms which were target like if used in the default form of the root infinitive were counted as target like inflectional forms.
} 
sessions that correspond to premorphology in the development of the child Nina were arbitrarily divided into two phases. Phase 1 consists of the first six recorded sessions, phase 2 consists of the last five recorded sessions. Results are given in figure (1) and (2).

A total of 64 tokens in which Nina combined a third person singular subject with a verb-form ending in -ing appeared in the first six sessions of the recordings. Only a total of seven first person singular references were found (table 11). Ultimately, the usage of the present progressive has to show subject-verb agreement. Figure 1 shows which kind of subject-NPs were produced by Nina. Only a small percentage, $17,2 \%$, appears with target-like agreement. The $17,2 \%$ are divided between ten utterances in which agreement is reached by the attachment of a suffix: in these cases ' $s$ is attached to the subject noun phrase. Only one utterance was found in which the present progressive is used in its full analytical form (36).

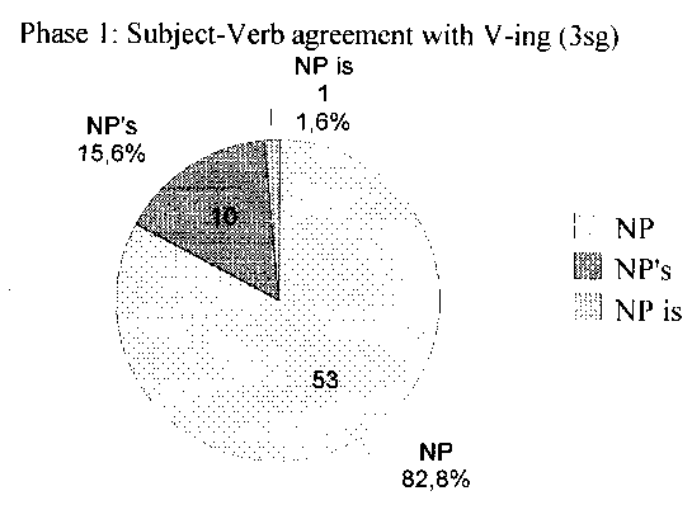

${ }^{*} \mathrm{CHI}$ : that horse is running. $(2 ; 0,3)$

Subject-verb combinations involving a progressive form become more accurate in phase 2 (figure 2). Although the absolute amount of -ing forms decreases towards the end of phase 2 (table 11), the relative amount of target like constructions with -ing increases. In the majority of cases the progressive is not used fully analytical, but the finite member occurs suffixed to the subject.

Regarding the child's first steps towards the acquisition of inflectional suffixes (-ing) plus agreement elements (the respective auxiliary) the following trend can be observed. The child sets off by using an -ing form when referring to third person singular, at first these constructions involve no auxiliary. Refernces to first person singular involving the suffix -ing are less numerous, reference to second person is almost non-existent. The next step is the acquisition of agreement factors. At this early stage these are reduced to the affixed version of auxiliaries. First and second person references with -ing forms are not used together with auxiliaries at all. It could be argued that in the process of the acquisition of verbal morphology the child first concentrates on third person singular references, which are specified by the use of a verb with the suffix -ing. Parallel to the Phase 2: Subject-Verb agreement with V-ing (3sg) slowly emerging use of -ing with first person and finally on second person references agreement factors begin to play a role in third person singular references(figure 3 ). The use of the auxiliary $i s$ or its affixed version is established before agreement with first and second person singular references is reached. 


\subsection{The first mini-paradigm}

The first mini-paradigm that fulfills the criteria menrtioned above occurrs in the data of Nina when she reaches an age of $2 ; 2$. At age 2;2 Nina uses a diversity of verb forms when she produces utterances with the verb to sleep. Nina's utterances which contain some form of the verb to sleep and which contribute to her first mini-paradigm will be discussed at some length here. On the one hand it can be shown that although a number of different constructions surface in Nina's grammar, she is still far from the stage of protomorphology. On the other hand it becomes clear that the trends which were established in Nina's verbal morphology before she reached an age of $2 ; 2$ become manifested and serve as a basis for further development.

The first point that needs to be mentioned is that the many occurrences of verb forms of to sleep are by no means coincidental in a sense that Nina happens to talk about 'sleeping' as well as other activities. Quite to the contrary, Nina spends a great deal of both session 15 and 16 talking about sleeping routines. This is due to the fact that she has had a lot of trouble going to sleep in the time of the respective recordings. It is thus not surprising that the first mini-paradigm is established with the verb to sleep. One could of course argue that if Nina produces three recurrent inflected forms for one verb if given enough chance to use it, the same results are theoretically possible for other verbs. Although this fact has be born in mind it is nevertheless not documented in the data.

In the sessions 13-16 of the recordings, Nina used a total of 106 utterances involving the verb to sleep or to go to sleep. Of these, 74 were either imperatives or utterances with an identifyable subject; 23 utterances were not analysed since they had no subject and 9 utterances were not analysed although they had a subject, since their meaning was idiosyncratic or opaque. Tables 15-20 show which categories were encoded by the verb forms used by Nina. Of the two numbers given, the first is the total of verb forms that occurred in the respective categories, the second is the number of those verb forms which were inflected and thus presented candidates for the formation of the first mini-paradigm ${ }^{6}$.

Table 15: present progressive 'sleeping'

\begin{tabular}{|l|l|l|}
\hline & sg & $\mathrm{pl}$ \\
\hline 1st & & \\
\hline 2nd & 1 & \\
\hline 3rd & $23 / 7$ & 3 \\
\hline
\end{tabular}

Table 16: infinitive forms 'sleep'

\begin{tabular}{|l|l|l|}
\hline & sg & pl \\
\hline 1 st & 1 & \\
\hline 2nd & & \\
\hline 3rd & 2 & \\
\hline
\end{tabular}

Table 17: infinitive forms 'go to sleep'

\begin{tabular}{|l|l|l|}
\hline & sg & pl \\
\hline 1 st & & \\
\hline 2nd & & \\
\hline 3rd & 2 & \\
\hline
\end{tabular}

Table 18: going-to-future 'going to sleep'

\begin{tabular}{|l|l|l|l|l|l|}
\hline & $\mathrm{sg}$ & $\mathrm{pl}$ & $\mathrm{sg}$ & $\mathrm{pl}$ \\
\hline $1 \mathrm{st}$ & 1 & & $3 / 3$ & \\
\hline $2 \mathrm{nd}$ & 1 & & & \\
\hline $3 \mathrm{rd}$ & $2 / 2$ & 2 & & & \\
\hline
\end{tabular}

\footnotetext{
6 The remaining utterances which are not listed in the tables are two questions and four compound constructions.
} 
Table 20: imperatives

\begin{tabular}{|l|l|}
\hline 'sleep' & $8 / 8$ \\
\hline 'go to sleep' & $9 / 9$ \\
\hline 'let me sleep' & $9 / 9$ \\
\hline
\end{tabular}

As the tables presented above show, there are several candidates which fill slots in the first mini-paradigm. These are inflected third person singular progressives as in (37), third person singular going-to-future constructions (38), three different kinds of imperatives (39)-(41) and a first person singular modal construction (42).

*CHI: and the man's sleeping on the big bed.

*CHI: father's going to sleep in playpen \# ok?

*CHI: you sleep \# Mommy.

*CHI: go to sleep \# Mommy.

(41) *CHI: let me sleep on you \# Mommy.

*CHI: I want to go to sleep.

The most important point to note is that although the child begins to use differernt inflected forms for one verb type, in no case is a person or number contrast established within one of the paradigms. Constructions which involve an auxiliary begin to develop in the third person singular (37)-(38). Auxiliaries for other persons and number play no role at all. The only other verb forms that are used with a target like function is the infinitive form of the verb used as an imperative and a modal construction restricted to first person singular.

\section{Conclusion}

It could be argued that the scarcity of inflectional affixes in English considerably reduces the statistical probability of different inflectional verb forms occurring. Although there is some truth in this and it was argued above that in the case of the infinitive form it is impossible to tell whether the child is using it target like or just as a default, both tables 10-13 and tables 15-20 illustrate that most categories are established a long time before they regularily become manifested in inflectional verb-forms. Although the first mini-paradigm could be identified when the child Nina had reached an age of $2 ; 2$ it could be shown that the slots which were filled did not contrast within one category. This is to say that although the child begins to use third person singular progressive forms with some regularity, she does not yet contrast them with other inflected form of the present progressive in terms of person and number. Quite to the contrary, verb forms are established independent of each other. This is an important point to note since it can still be argued that the child has not discovered English verbal morphology but is still drawing heavily on rote learned forms. From a typological perspective this is a strong argument for the hypothesis that children who acquire a language with little morphology do not use inflected forms regularily for a relatively long period of time.

Regarding the acquisition of the entire (inflectional) morphological system, an interesting aspect of Nina's morphological development is her acquisition of the personal pronouns. Budwig $(1989,1995)$ has shown that non-target use of $m y$ is produced by children acquiring English as their first language for the marking of agentivity and control. Nina's use of $m y$ in 
subject position (43)-(44) is not given up until she reaches an age of 2;6 and the development of her syntax allows her to use structures like (45)-(46) to mark her control of a certain action.

*CHI: my do it.

*CHI: my gonna make a egg.

${ }^{*} \mathrm{CHI}$ : you do it by yourself.

${ }^{*}$ CHI: I like to pick monkeys by myself.

$(2 ; 11,6)$

Sentences (43)-(46) illustrate that Nina uses two entirely different constructions for a similar function. At early stages of language acquisition she uses non target my in subject position to express that she rather than anybody else wants to carry out a certain action. It should be mentioned that at the same time Nina uses my target like in possessive constructions. As soon as Nina's language skills have matured in a sense that she can use a target like construction for the expression of control in a certain action, namely the adverbial exclusive intensifier, her non target use of the personal pronoun $m y$ is given up. Regardless of the precise mechanisms of Nina's syntactical development that allows her to use structures like (45)-(46) it is an important point to note that case is not mastered by Nina before age 2;6. Parallel to the development of verbal inflections, case emerges relatively late in the data of Nina.
(47) I feed Tim.
(48) Me feed Tim.
(49) My feed Tim

(50) Ich füttern Tim.

(51) Mich füttern Tim.

(52) Mein füttern Tim.

Although this phenomenon must be investigated in more detail, it is an interesting correlation that a child acquiring English, a language with only a few inflections but a stable word order, will learn to use verbal and (nominal)/pronominal inflection relatively late. Word order in English makes decodation of utterances such as (47)-(49) fairly easy since the subject is to be expected sentence initial. This option is not given in German which allows objective case in the first position. Regarding parallel sentences such as English (47)-(49) and German (50)-(52), the English constructions are unambiguous and all surface in the acquisition data of children. The German sentences (50)-(52) on the other hand cannot all be interpreted as straightforward. While sentence (47) and (50) have a parallel interpretation, sentence (51) is most naturally interpreted with Tim being subject and mich being the object. The meaning of sentence (52) is not quite clear and possibly ambiguous. Neither sentence type (51) nor sentence type (52) surface regularly in the acquisition data of German children.

\section{Literature}

Budwig; Nancy (1989): The linguistic marking of agentivity and control. Journal of Child Language $16,263-284$.

Budwig, Nancy (1995): A developmental-functionalist approach to child language. Mahwah: Lawrence Erlbaum.

Bittner, Dagmar (this volume): Emergence of verb inflection in one German child.

Bittner, Dressler \& Kilani-Schoch (this volume): Introduction.

Kilani-Schoch (this volume): Early verb development in two French-speaking children.

König, Ekkehard (1991): The meaning of focus particles: A comparative perspective. London: Routledge.

Tomasello Michael (1992): First Verbs. Cambridge: Cambridge University Press. 